\title{
Teams and Projects: A Literature Review
}

\author{
Guru Prakash Prabhakar \\ Bristol Business School \\ University of the West of England \\ Coldharbour Lane, Frenchay Campus \\ Bristol- BS16 1QY, UK \\ Tel: 44-117-328-3461Ｅ-mail: guru.prabhakar@uwe.ac.uk
}

\begin{abstract}
Teams and their constituents are clearly one of the critical success factors in a project. Symbiosis among team members is a must, but it does not necessarily mean that they need to agree on every point. This paper attempts to highlight the constituents of a team, criteria for tem membership, team climate and the role of a project manager in leading teams.
\end{abstract}

Keywords: Project teams, Project manager, Project leader

\section{What is the meaning of the term "Team"?}

Verma (1997) describes team approach as a distinctive way of working that harnesses the collective skills, strengths, and energy of team members.

Robinson \& Robinson (1994) and also Thamhain (1988) define a team as a group of people, but all groups do not qualify as teams. At times, a group may be formed just for administrative purposes or for achieving personal goals or for social affiliation. At other times, committees can stifle creativity and hinder decision-making. However, occasionally, a group of people combine high morale, effective task performance and a clear relevance to the organization. A team is a group of people who work interdependently, who are committed to common goals, and who produce high quality results.

Katzenbach and Smith (1994) defined a team as "A small number of people with complementary skills who are committed to a common purpose, performance goals, and common approach for which they hold themselves mutually accountable."

Teamwork is a symbiotic process which leads to a much better result that is greater than the integration of individual performances. Thamhain (1988) describes effective teams as the ones that produce high quality results and succeed in spite of many difficulties and cultural or philosophical differences. Effective teams have several task-oriented and people-oriented characteristics. Thamain (2004) debates that the working environment within the project team has a significant impact on project success, and therefore suggests that the project manager has a significant leadership role in blending the team.

One of the most important responsibilities of project managers is to build effective teams. Team building is a process of transforming a group of individuals with different interests, backgrounds, and expertise into an integrated and effective work unit. Although this process varies complexity, nature and size of project.

In the book Harvard Business Essentials (2004) the success of project work is naturally affected by the people who participate. A good management and a sound organizational structure matters. But neither will produce a satisfactory outcome if the right people are not on board - or if those people are not clear o their roles. I try to broadly describe the main players on a project with the characteristics of effective project managers and project teams.

\section{Project Manager}

Every project has a single manager. The project manager is the individual charged with planning and scheduling project task and day-to-day management of project execution. He or she is also the person with greatest accountability for the endeavour's success. This person receives authority from the sponsor and plays a central role in each phase of the project's life cycle, from design and organization to project closedown and evaluation- and everything in between.

A project manager has many activities to be performed, for example:

(1) Recruit effective participants 
(2) Provide a framework for the project's activities

(3) Keep the vision clear

(4) Coordinate activities

(5) Negotiate with higher authorities, and with the sponsor in particular

(6) Mediate conflicts

(7) Identify needed resources

(8) Set milestones

(9) Manage the budget

(10) Ensure that everyone contributes and benefits

(11) Keep work on track; and

(12) Assure that project goals are delivered on time and on budget.

\section{Project Team Leader}

A leader emerges, whereas a manager is appointed. This means that a leader has power or influence on individuals in a team whereas a manager exercises authority which is vested in his or her position. A leader commands respect due to his or her influence which could be due to soft or hard skills or a combination of both. Sometimes large projects are organized to include a project team leader who reports directly to the project manager, as shown in the figure below. In small projects, the project manager wears both hats.

The team leader cannot act like the boss and still obtain the benefits normally associated with team-based work. Instead, the team leader must adopt five important roles:
(1) Initiator
(2) Model
(3) Negotiator
(4) Listener and
(5) Coach.

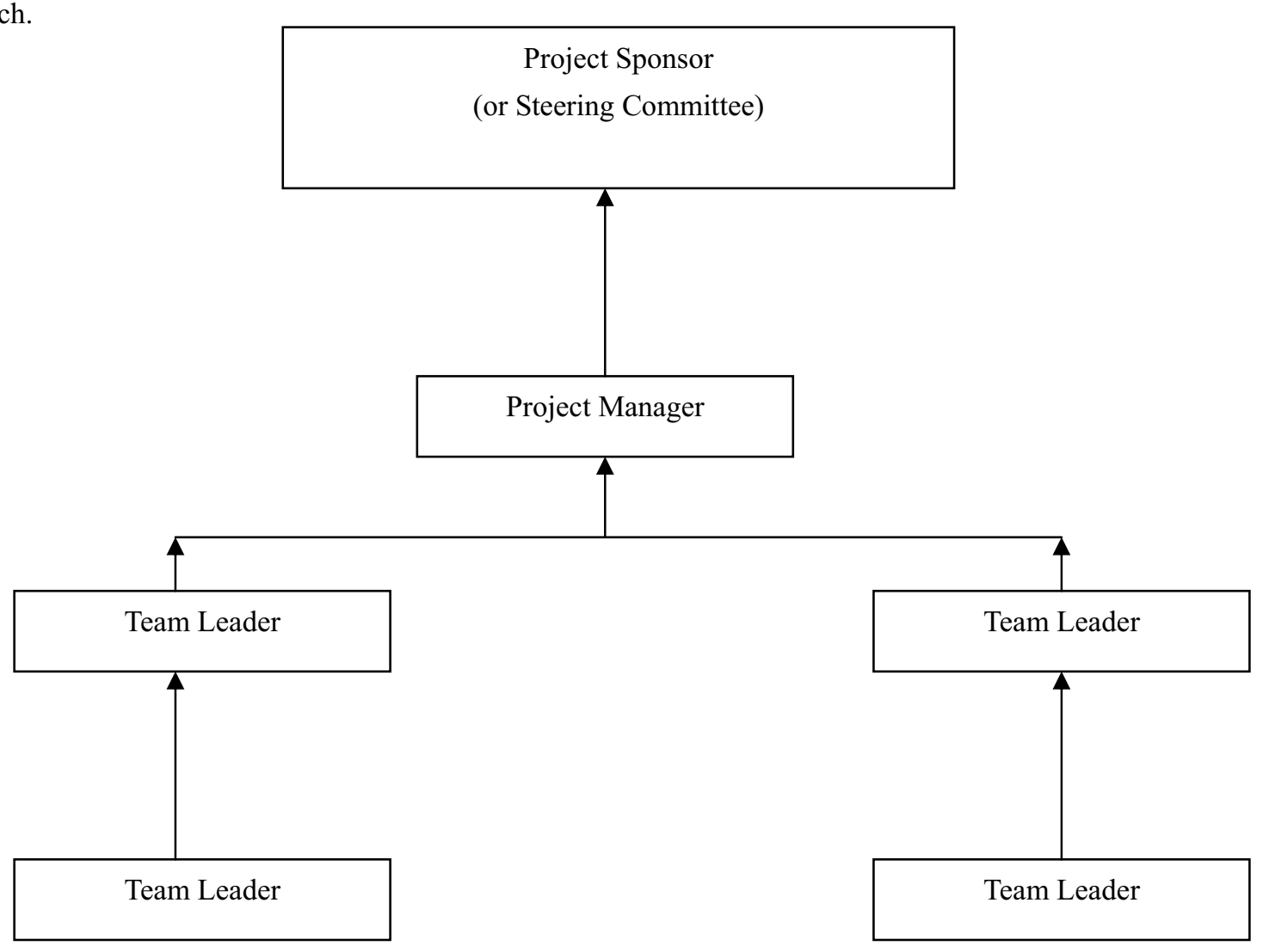

Exhibit 1: Project Hierarchy: Extracted from Harvard Business Essentials (2004) 


\section{Criteria for Project Team Membership}

A specific skill set is a must to have for project team members that differs from one project to another. Broadly the skills needed could fall under the following general categories:

(1) Technical skills

(2) Problem-solving skill

(3) Interpersonal skill

(4) Organizational skill

\section{Characteristics of Effective Project Teams}

Apart from the particular skills that people bring to a project, what else should one look for? The literature on team-based work provides some insights. That literature points to several qualities as ingredients in team or project success. They are:

Competence

A clear and common goal

Commitment to the common goal

An environment within which everyone contributes and everyone benefits

A supportive structure

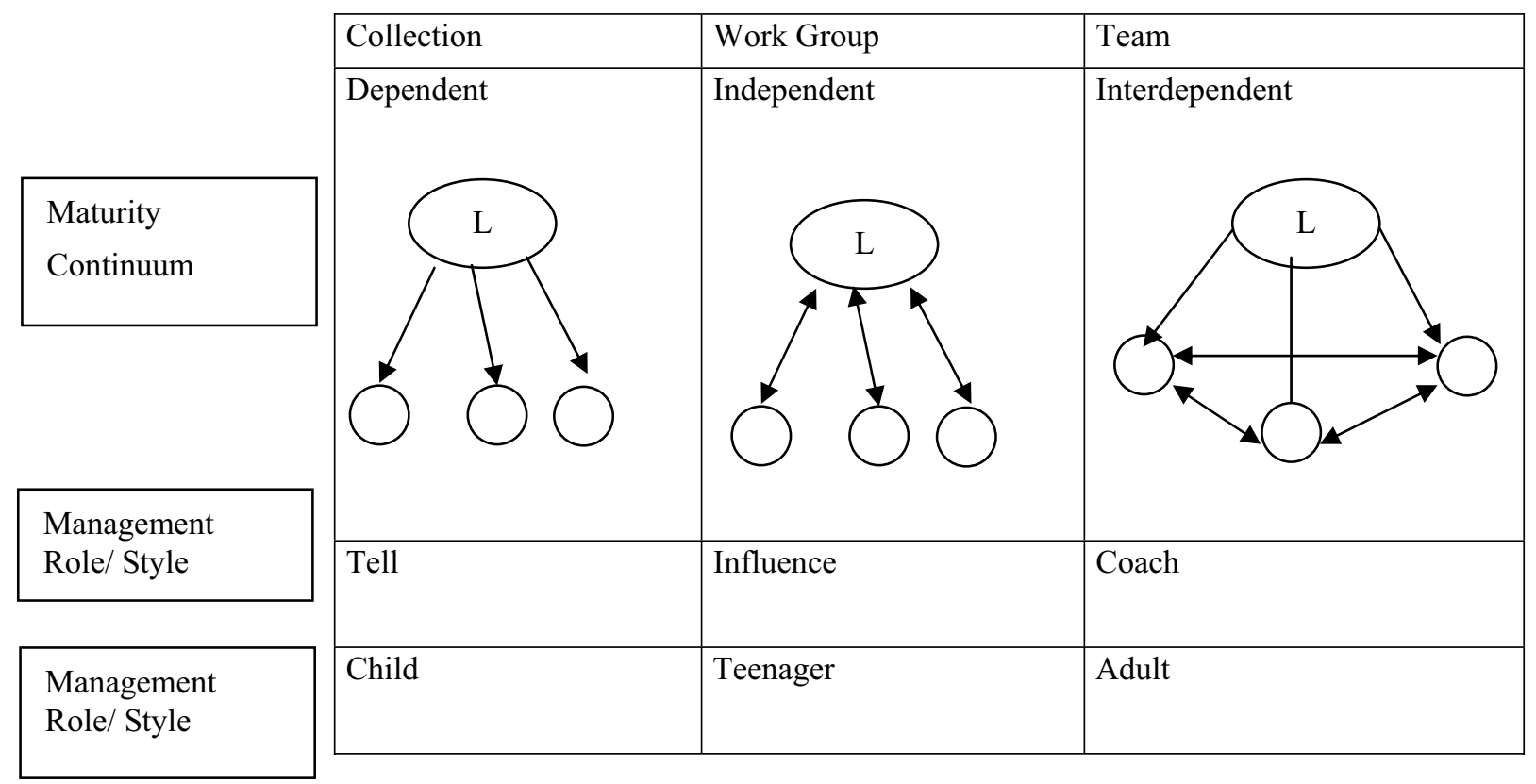

Exhibit 2: How a team differs from a group and a collection of people. Extracted from Verma (1997).

According to Verma (1997), operating in the 21 st century, project managers face the challenges of operating in a project environment characterized by high levels of uncertainty, cross-cultural teams, and global competition. A clear understanding of human aspect in project management and its effective use are required to inspire project stakeholders to work together in order to meet and beat project objectives.

As indicated by Flaatten, McCubbrey, O’Riordan and Burgess (1992), project team members are selected according to the skill requirements for the particular phase being undertaken. How many roles are identified and how specific they are depends mostly on the size and the complexity of the project. Small projects are informally organized, with each team member potentially capable of playing any of the roles.

Medium-sized teams have a more rigorous specialization. This specialization may be along functional or technical lines. Large projects need both functional and technical subdivisions at the same time. In addition, project management is usually not performed by a single individual. The project leader represents the team to the outside and implements the steering committee's decisions. He or she also defends the project team vis-à-vis the steering committee. Other team member roles are dictated by the nature of the work to be performed and the skills required. 


\section{Team Climate}

Reddin (1988) says that the team climate is characterized by interaction between individuals and units. The climate places a high value on communication in group settings. It is not just two-way communication that is important, but also communication multi-way, upwards, down-wards and laterally. There is less concern than average about power differentials between individuals or units.

Verma $(1995,1996)$ brings out the important interpersonal skills required to be a project manager that are: communication, team building, coaching, motivating, decision-making, delegating, training, directing, persuading/influencing, negotiating, and supporting those involved in the project. Project managers must establish a climate of open communication and maintain effective communication links across the organizational interfaces.

Various researchers, for example, Badaway (1982), Einsiedel (1987), Thamhain (1991) have found out that project management requires expertise and skills in three primary areas:

Leadership and interpersonal

Administrative

Technical

Verma $(1995,1996)$ argues that successful project managers combine the three above mentioned skill types. Kloppenborg and Petrick (1999) suggest that project leaders have a role in developing team characteristics into a collective set of virtues including:

- Ethics

- Respect and trust for others

- Honesty

- Prudence

- Courage

- Responsible use and sharing of power.

Thus, from the preceding discussion it is clear that leadership plays an important role in team-performance. It helps a team function as a well-knit unit as opposed to a group of individuals.

\section{Team Dynamics}

Let us examine another highly dynamic aspect in the project leadership situation; the changing team and work needs that a project manager must combine to produce a successful outcome. Tuckman's (1965) team development model draws attention to distinct phases of group transformation and development commonly referred to as the forming, storming, norming and performing stages.

Tuckman (1965) believes the team development process can be sub-conscious but if the group is aware of the stages then the team can be more effective more rapidly. This quicker extra performance is of particular interest in project management. Leaders should be able to identify the cycle of their team to know when it is likely to be the highest performing and also when it will tend to lack motivation. The forming stage involves identifying the task and accomplishing it. The group gathers information about the tasks and other team members. There is discussion on the standard organizational processes and people are concerned with routines and organizational issues.

Tuckman (1965) does not believe that there is much task accomplishment at this stage, so perhaps not the best stage for a project management team to linger in. As the team advances into the storming stage, the group members argue amongst themselves, whether they agree or not on the immediate tasks to be performed. There is discord, tension and powerplays.

In the third phase, norming, the task goal takes priority over individual quarrels and there is more willingness to adhere to the group and avoid conflict so discussions are friendlier. People listen more to each other and the team is able to develop group processes that start to produce a more practical level of task performance.

Performing sees the individual changing his behaviour in accordance with group and task needs. The group learns how to solve conflicts so that it can move on with the task in hand. There is interdependence and flexibility. The processes are carefully refined to produce a high level of performance.

Awareness of the forming, storming, norming and performing cycle can be useful to a project manager. Verma (1997) thinks that progress from one stage to the next may vary from team to team, influenced by the maturity level of the team members, the project manager and overall project environment. He believes that the project manager must move the team along the cycle to the last performing stage as fast as possible. 
On a project, the time factor is a powerful driver both in terms of task time constraints and pressure on the individual. Pinto and Thoms (1999) argue that project leaders must possess or develop temporal skills that align with the various tasks and situations that they must deal with to improve their chances for success. This time influence also has a clear effect on the team dynamics during the project. This impact could go so far as to affect the widely accepted team development model of forming, storming, norming and performing. Tuckman (1965) noted that time pressure has an effect on the group transformation process that could shape the cycle.

\section{Conclusion}

To summarise, a skilful project team management is vital to project execution. A team goes through different stages of development during the tenure of a project. A constructive team climate would motivate the team members and the same will reflect on the overall team performance. Good leadership plays an important role in creating a positive team ambience.

\section{References}

Badaway, M.K. (1982). Developing Managerial Skills in Engineers and Scientists, New York: Van Nostrand Reinhold.

Einsiedel, A.A., Jr. (1987) Profile of effective project managers, Project Management Journal, pp. 51-56.

Flaatten, P.O., McCubbrey, D.J., O’Riordan, P.D. and Burgess, K. (1992). Foundations of Business Systems (second edition),Andersen consulting Arthur Andersen \& Co., S.C., The Dryden Press.

Harvard Business Essentials (2004). Managing Projects Large and Small: The Fundamental Skills for Delivering on Budget and on Time.

Katzenbach, J.R. \& Smith, D.K. (1994). The Wisdom of Teams, HarperCollins, New York, pp. 1-148.

Kloppenborg, T. J., \& Petrick, J. A. (1999). Leadership In Project Life Cycle \& Team Character Development, Project Management Journal, 30(2), p. 8.

Pinto, J. K., \& Thoms, P. (1999). Project leadership: A question of timing. Project Management Journal, 3(1).

Reddin, B. (1988). The output oriented organization, Gower publishing company limited, p.73.

Robinson, G. \& Robinson, S. (1994). Notes and handouts for project management course sponsored by the School of Engineering Science and presented by the department of Continuing Studies, Simon Fraser University, pp.6-14.

Thamhain, H.J. (2004). Linkages of project environment to performance: Lessons for team leadership. International Journal of Project Management, 22(7), 533-544.

Thamhain, H.J. (1991). Developing project management skills, The Project Management Journal, pp. 39-44.

Thamhain, H.J. (1988). Team Building in Project Management, Project Management Handbook, Second Edition, Eds. Cleland D.I and King, W.I., New York: Van Nostrand Reinhold, pp.8-15.

Tuckman, B. (1965). Developmental sequence in small groups. American Psychological Association, Psychological Bulletin, 63(6), pp. 384-399.

Verma, V. K. (1997). Managing the project team. Project Management Institute. Newtown Square, PA. pp. 72.

Verma, V. K. (1996). Human resource skills for the project manager. Project Management Institute. Newtown Square, PA.

Verma, V.K. (1995). Organizing projects for success. Project Management Institute. Newtown Square, PA. 